\title{
A CASE OF NEPENTHES RAFFLESIANA WiTH A LOTUS-LIKE FLOWER!
}

Jorge JoEL TorRes-RiverA • 324 Tejas Street • URB. San Gerardo • San Juan, PR $00926 \bullet$ USA

•jardin_emilia@hotmail.com

Keywords: ecology: cultivation: Nepenthes rafflesiana - observations: Nepenthes rafflesiana.

The first Nepenthes I ever grew was a specimen of $N$. rafflesiana that I bought in 2003 from a local nursery in Puerto Rico. This plant did well, and encouraged me to grow more carnivorous plants. My collection of Nepenthes and other carnivorous plants grew. Many of my Nepenthes started to produce flowers, but despite my luck with these other plants, my very first-ever Nepenthes purchase refused to flower. It produced many pitchers with increasingly large size, and its leaves were huge. It was very healthy in my outdoor growing house, which has no walls but a roof that helps filter sunlight. Exposed to the climate, the plant loves the humid and warm weather of Puerto Rico. Yet, it did not flower!

Finally, in the spring of 2006 my beloved N. rafflesiana did the magic. I noticed a protuberance at the base of the growing point, which finally developed into an inflorescence. However, even at an early stage I could see the inflorescence was different from the ones I had seen on my other Nepenthes plants; it was bigger and fatter than normal. As it enlarged, I saw it did not consist of many little flowers in a crowded panicle, but was instead a group of sepals enclosing a single fat and lonely flower. By no means it was similar to the typical Nepenthes inflorescence!

When the sepals opened it revealed a single huge stamen shaped like a dark wine-colored mushroom, surrounded by more than a dozen sepals. To me it looked more a flower from a lotus (Nuphar sp.) than that of a Nepenthes! The stamen produced pollen, but I did not have a female plant in flower to test if it was viable. After several days the pollen faded, but the flower stayed apparently fresh.

I wondered-were all the flowers from this plant going to be so strangely abnormal? I could only wait for the next inflorescence to see! It was not until the autumn of the same year that the plant finally produced a new inflorescence. It was a normal male inflorescence. As I write this (in late December 2006), this inflorescence is starting to fade, but the original lotus-flower still looks as fresh as when it first opened!

Now I am waiting for the next flowering of this plant. Will the flower be normal, or will it be another oddity? And what caused the strange flower in the first place? An interesting mystery!

If you want to see other images of my lotus-flowering Nepenthes rafflesiana, you can visit my tropical and exotic plants nursery eBay web site (Emilia's Garden; http://stores.ebay.com/EMILIAS-GARDEN). 


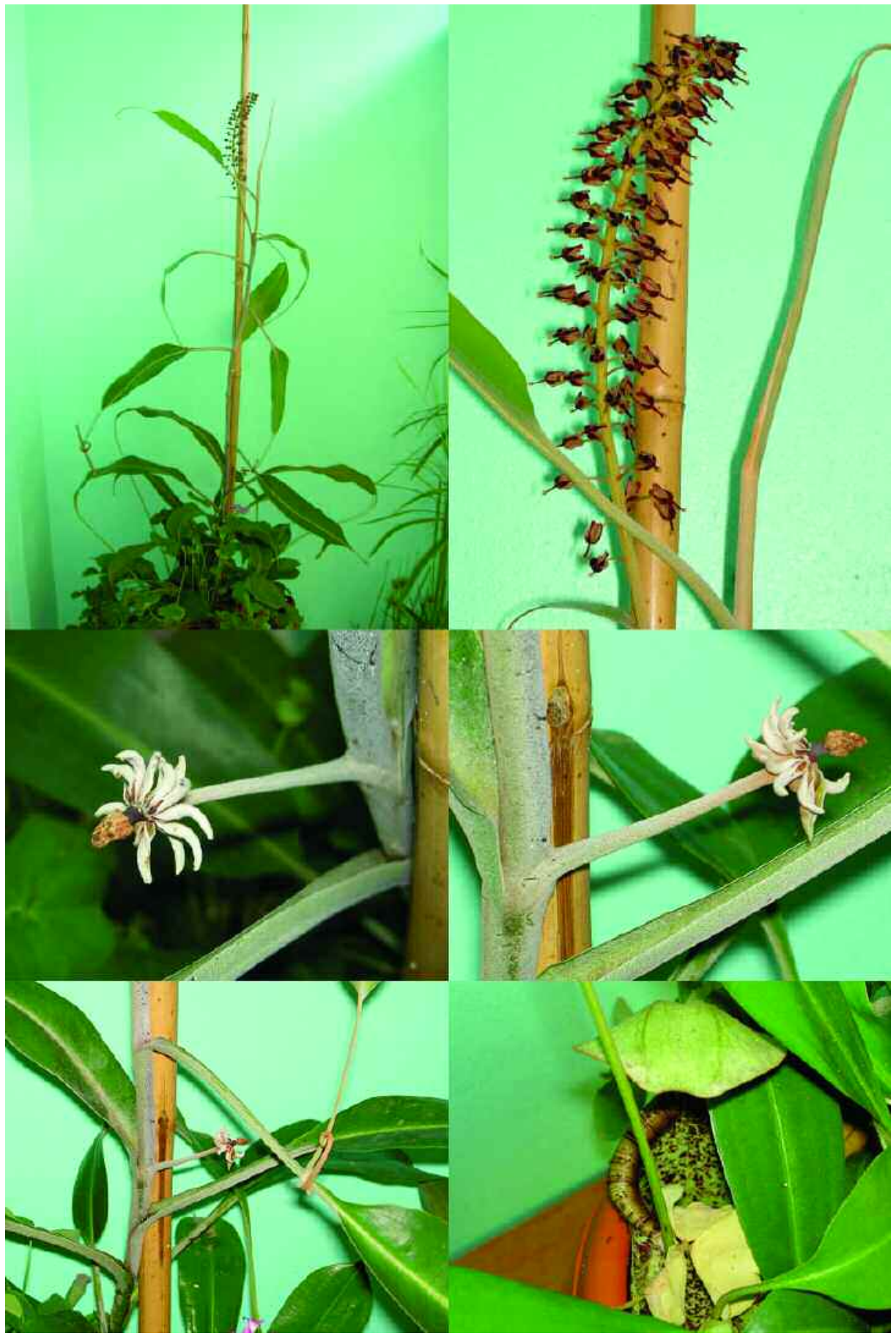

Figure 1: Different views of the Nepenthes rafflesiana plant, its normal inflorescence, and the strange lotus-like abnormal flower. 